\title{
Konum Tabanlı Mobil İletişimlerin Benimsenmesini Etkileyen Faktörler Üzerine Bir Araştırma (A Research on the Factors Affecting Adaption of Location Based Mobile Communications)
}

\author{
İbrahim BOZACI (iD) a, Rukiye Nur BEĞDEŞ (iD) b \\ a Kırıkkale Üniversitesi, Keskin Meslek Yüksekokulu, Kırıkkale, Türkiye. iborganizer@gmail.com \\ ${ }^{\mathrm{b}}$ Kırıkkale Üniversitesi, Sosyal Bilimler Enstitüsü, Kırıkkale, Türkiye. beydesrukiye@gmail.com
}

\begin{tabular}{|c|c|}
\hline MAKALE BİLGİSİ & ÖZET \\
\hline $\begin{array}{l}\text { Anahtar Kelimeler: } \\
\text { Konuma Dayalı } \\
\text { İletişim } \\
\text { Tüketici } \\
\text { Benimseme } \\
\text { Konum Tabanlı Mobil } \\
\text { Pazarlama }\end{array}$ & $\begin{array}{l}\text { Amaç - Günümüzde artan teknolojik gelişmelere bağlı olarak mobil iletişim araçlarının kullanımı } \\
\text { yaygınlaşmaktadır. İşletmeler, müşterilerine ulaşmak için konum tabanlı mobil iletişimlerden } \\
\text { yararlanmaktadır. Ancak, konum tabanlı teknolojilerden yeterince yararlanılması, tüketicilerin } \\
\text { konum tabanlı iletişimleri benimsemesine bağlıdır. Bu noktada, tüketicilerin konum tabanlı } \\
\text { iletişimleri kullanması ve mobil uygulamaların konum tabanlı özelliklerini benimsemesini } \\
\text { engelleyen faktörlerin bilinmesi gerekmektedir. Bu araştırma, tüketicilerin konum tabanlı mobil } \\
\text { iletişimleri benimsemesini etkileyen faktörlerin anlaşılması amacıla yapılmıştır. }\end{array}$ \\
\hline Gönderilme Tarihi 6 Temmuz & $\begin{array}{l}\text { Yöntem - Araştırma kapsamında Kırıkkale Üniversitesi, İktisadi ve İdari Bilimler Fakültesi } \\
\text { öğrencilerinden kolayda örnekleme yöntemi ile birincil veriler toplanmış, elde edilen veriler } \\
\text { istatistiksel paket programı ile analiz edilmiş ve araştırma bulguları yorumlanmıştır. }\end{array}$ \\
\hline $\begin{array}{l}\text { Revizyon Tarihi } 9 \text { Eylül } 2019 \\
\text { Kabul Tarihi } 15 \text { Eylül } 2019\end{array}$ & $\begin{array}{l}\text { Bulgular - Araştırma sonuçlarına göre; olumlu tutum, algılanan rasyonel fayda ve algılanan } \\
\text { kolaylık faydasının konum tabanlı mobil iletişimleri benimsemeyi pozitif yönde etkilediği tespit } \\
\text { edilmiştir. Ayrıca gizlilik endişesinin, konum tabanlı mobil iletişimleri benimsemeyi olumsuz } \\
\text { etkilediği anlaşılmıstır. Diğer taraftan farkındalığın, konum tabanlı mobil iletişsimleri benimsemede } \\
\text { önemli değişken olmadığı görülmüştür. }\end{array}$ \\
\hline Araştırma Makalesi & $\begin{array}{l}\text { Tartışma - İşletme ve mobil uygulama geliştiricilerinin konum tabanlı mobil uygulama } \\
\text { özelliklerinden amaçladığı sonuçlara ulaşmasında ve özellikle genç tüketicilerin konum tabanlı } \\
\text { mobil iletişimleri benimsemesini sağlamada; konum tabanlı hizmetlere yönelik olumlu tutum } \\
\text { oluşturma, konum tabanlı iletişimlerin rasyonel ve kolaylık faydalarını vurgulama ve akıllı telefon } \\
\text { kullanıcılarının gizlilik endişelerini giderici önlemler almanın yararlı olacağını araştırma bulguları } \\
\text { göstermektedir. }\end{array}$ \\
\hline
\end{tabular}

\begin{tabular}{|c|c|}
\hline ARTICLE INFO & ABSTRACT \\
\hline $\begin{array}{l}\text { Keywords: } \\
\text { Location Based } \\
\text { Communication } \\
\text { Consumer } \\
\text { Adoption } \\
\text { Location Based Mobile } \\
\text { Marketing }\end{array}$ & $\begin{array}{l}\text { Purpose - Nowadays, the use of mobile communication tools has become widespread due to } \\
\text { increasing technological developments. Firms benefit from location based mobile communications } \\
\text { to reach their customers. However, the sufficient utilization of location based technologies, depends } \\
\text { on the adoption of location based communications by consumers. At this point, the factors should } \\
\text { be known that prevent consumer from adoption of location based features of mobile applications } \\
\text { and using location based communications. This research was conducted to understand the factors } \\
\text { affecting the adoption of location based mobile communication. }\end{array}$ \\
\hline $\begin{array}{l}\text { Received } 6 \text { July } 2019 \\
\text { Revised } 9 \text { September } 2019\end{array}$ & $\begin{array}{l}\text { Design/methodology/approach - Within the scope of the research, primary data were collected } \\
\text { from the undergraduate students of Faculty of Economics and Administrative Sciences of Kirikkale } \\
\text { University, by convenience sampling method, the obtained data were analyzed by statistical } \\
\text { package program and the research findings were interpreted. }\end{array}$ \\
\hline $\begin{array}{l}\text { Article Classification: } \\
\text { Research Article }\end{array}$ & $\begin{array}{l}\text { Findings - According to research results; it has been determined that positive attitude, perceived } \\
\text { rational value and perceived convenience value affects the adoption of location based mobile } \\
\text { communications positively. Moreover, it has been seen that privacy anxiety negatively affect the } \\
\text { adoption of location based mobile communications. On the other hand, it is seen that awareness is } \\
\text { not an important variable in the adoption of location based mobile communications. }\end{array}$ \\
\hline & $\begin{array}{l}\text { Discussion - To enable business and mobile application developers to achieve their intended results } \\
\text { from location-based mobile application features, and in particular to enable young consumers to } \\
\text { adopt location-based mobile communications; research findings suggest that it would be beneficial } \\
\text { to create positive attitudes towards location-based services, to emphasize the rational and } \\
\text { convenience values of location-based communication, and to take measures to alleviate privacy } \\
\text { concerns of smartphone users. }\end{array}$ \\
\hline
\end{tabular}




\section{GİRIŞ}

Konum bilgisinin takibi, taşımacılık ve kargo hizmetlerinde araçların takibinde kullanılmaya başlanmış ve güvenlik, yol yardımı, insan takibi, reklamcllık gibi alanlarda kullanılır hale gelmiştir (Barnes, 2003: 63). Konum tabanlı hizmetler; bilgi/rehber hizmetleri, izleme ve navigasyon hizmetleri, acil durum hizmetleri ve konum tabanlı reklam başlıklarında toplanmaktadır. Bilgi/rehber hizmetleri müşterileri; en yakın hastane, restoran, AVM, ATM, akaryakıt istasyonu veya eczane gibi işletmeler hakkında bilgilendirir. İzleme ve navigasyon hizmetleri; çocukların veya kaybolan evcil hayvanların takibi veya sesle bütünleştirilmiş rota tanımlama gibi hizmetlerden oluşur. Acil durum hizmetleri ; yol yardımı, arama kurtarma görevleri, ambulans gibi hizmetlere ulaşmayı sağlar. Konum tabanlı reklamlar ise; kupon sunumları, hedefli ve kişiselleştirilmiş reklamların konum bilgisine dayalı olarak sunulmasını ifade eder (Dhar ve Varshney, 2011: 124).

Mobil cihazlarda yer alan konum tabanlı uygulamalar, kullanıcıların konum bilgisini kullanarak yeni bir iletişim biçiminin oluşmasına neden olmaktadır (Şahoğlu, 2018: 259). Günümüzde hızla gelişen teknoloji, üretici ve tüketicileri yakından ilgilendirmektedir. Özellikle müşterilerin bulunduğu konum bilgilerinin kullanılabilir hale gelmesi, işletmelerin daha önce mümkün olmayan şekilde müşterilere ulaşmasına imkân vermektedir. Bu teknolojik imkânlardan yeterince yararlanma veya bunları etkin olarak kullanma, tüketicinin konum bilgisini işletmelerle paylaşmasına veya mobil uygulamaların konum tabanlı özelliklerini benimsemesine bağlıdır. Dolayısıyla tüketicinin konum bilgisine erişim izin vermesini etkileyen faktörler, pazarlama bilim adamlarının dikkatini çeken güncel konulardan biri olarak karşımıza çıkmaktadır.

Doğru yer ve zamanda, doğru hedef kitleye mesajları göndermek, pazarlamada temel konulardan olup, bu doğrultuda konum tabanlı pazarlama hizmetleri kullanılmaktadır (Tezcan ve Yengin, 2018: 113). Örneğin, işletmenin belirli bölgede gerçekleştirdiği şube açılışını, indirim kampanyasını veya yarışma programını bölge yakınındaki müşterilere veya bölgeye yaklaşan müşterilere haber vermesi mümkündür.

Konum tabanlı mobil pazarlamanın bir aracı olarak konum tabanlı reklamlar, müşterileri kişisel, anlık ve doğru mesajlarla davranışa teşvik eder. Akıllı telefon ve tablet bilgisayar kullanımının yaygınlaşması ve konumlandırma teknolojilerinin gelişmesine karşın, konum tabanlı reklamlara yönelik tutumlar ve özellikle gizlilik endişeleri önemli sorunlar olarak ifade edilir. Ayrıca, müşterilerin mobil reklamlara dikkatini vermediği ve reklamı görseler bile ihtiyaç veya istekleriyle ilgili olmadığında davranışlara etki etmediği görülmektedir (Kini ve Suomi, 2018: 67).

Her ne kadar müşterinin konum bilgisini işleyen konum tabanlı uygulamaların etkili ve verimli olması gibi faktörlere bağlı olarak işletmeler tarafından kullanımı artsa da (Ververidis ve Polyzos, 2002: 1 ; Tezcan ve Yengin, 2018: 113), konum tabanlı mobil hizmet ve iletişimlerin kullanımının yaygın olmadığı ifade edilmektedir (Junglas ve Watson, 2008: 387). Diğer taraftan, akıllı telefon kullanıcılarının, konum tabanlı iletişimleri kullanması, işletmeler için müşterilerle etkili iletişimler kurmada önemli fırsatlar sunmaktadır.

$\mathrm{Bu}$ araştırmanın amacı, tüketicinin konum tabanlı mobil iletişimleri benimsemesini etkileyen faktörlerin anlaşılmasına katkı sağlamaktır. Böylece konum tabanlı mobil pazarlamanın yaygınlaşmasının önündeki engellere ve benimsenmesindeki teşvik edici faktörlere dikkat çekilmektedir. Ayrıca araştırmada, mobil uygulamaları görece daha fazla kullanan üniversite öğrencilerinin, konum tabanlı iletişimlerden yararlanmasını artırmak için öneriler geliştirilmektedir.

\section{HIPOTEZ GELIŞTIRME}

Tüketicinin eğilim ve davranışlarıyla ilgili gerçekleştirilen araştırmalar, algılanan faydanın tüketicilerin davranışsal niyetini (satın alma eğilimi, kullanma eğilimi vb.) etkileyen önemli bir değişken olduğunu göstermektedir (Kuo vd., 2009: 66; Ashton vd., 2010: 206, Raza vd., 2012: 788, Eskiler ve Altunışık, 2015: 483). Teknolojik ürünlerin ve ürünlerle ilgili yeniliklerin kabulüyle ilgili araştırmalar da, yeni ürün ve uygulamaların kullanılma eğiliminin algılanan fayda ile yakından ilişkili olduğu fikrini desteklemektedir (Shaharudin vd., 2010: 70 , Wu vd., 2014: 2768; Hsu ve Lin, 2015: 46; Ponte vd., 2015: 286). Ayrica, müşterinin konum tabanlı hizmet ve mobil uygulamaları kullanma eğilimi ve kullanma devamlılı̆ının, algılanan fayda ile ilişkili olduğu da çeşitli araştırmalarda desteklenmiştir (Yu vd., 2013: 711, Kang vd., 2015: 210). Pura (2005: 509) müşterinin algıladığı parasal değer ve kolaylık değerinin konum tabanlı hizmetlere yönelik davranışsal eğilimi etkilediği sonucuna ulaşmıştır. Richard ve Meuli (2013: 698) ise üniversite öğrencilerinin konum 
tabanlı reklamları benimsemede, eğlendiricilik ve bilgilendiricilik gibi faydaların önemli olduğu sonucuna varmıştır.

Neticede tüketicinin zihnindeki konum tabanlı iletişimlerin kendisine zaman kazandırdığı, daha doğru tercihler ve daha kolay alışverişler yapmasına neden olduğuna yönelik algılamaların, bu iletişimleri benimsemesini etkilemesi beklenmektedir. Araştırmanın birinci hipotezi bu doğrultuda oluşturulmuştur:

Hı: Algılanan fayda (rasyonel, duygusal, kolaylık), mobil uygulamalar aracılığıyla konum tabanlı mobil iletişimleri benimsemeyi etkilemektedir.

Konum tabanlı mobil iletişimlerin benimsenmesinde ikinci olarak, gizlilik endişelerinin etkili olduğu düşünülmektedir. Zira Bozacı'nın (2015: 612) araştırması, müşterinin gizlilikle ilgili sahip olduğu düşünce ve duyguların (endişe vb.), bilgi sağlanması gereken alışverişlere (internet üzerinden satın alma) yönelik eğilimleri olumsuz etkilediğini göstermektedir. Ayrıca konum tabanlı mobil uygulamaları kullanma niyetinde gizlilik endişesinin önemli bir faktör olduğunu gösteren araştırmalar vardır (Junglas vd., 2008: 387; Basheer ve Ibrahim, 2010: 28; Zhou, 2011: 212: ; Xu vd., 2011: 42). Zhou (2011) gizlilik kaygilarının (toplama, hatalar, ikincil kullanım, uygunsuz erişim, kontrol ve farkındalık), konum tabanlı hizmetleri benimsemede etkili olduğu sonucuna varmıştır. Beldona ve diğerleri (2012: 86) de seyahat eden müşterilere anket uygulayarak gerçekleştirdiği çalışmasında, bilgi gizliliğinin, konum tabanlı pazarlama programlarını etkilediği sonucuna ulaşmıştır.

Kısaca kişisel bilgilerin toplanması, bunların yetkisiz şekilde kullanılması veya bunlara başka kişi veya firmalar tarafından kullanılması gibi durumlardan tüketicinin endişe duymasının, konum tabanlı iletişimleri benimsemesini etkilemesi beklenmekte ve araştırmanın ikinci hipotezi gizlilik endişesinin etkisine yönelik tasarlanmaktadır:

$\mathrm{H}_{2}$ : Gizlilik endişesi, mobil uygulamalar aracılığıyla konum tabanlı iletişimleri benimsemeyi olumsuz etkilemektedir.

Tüketici davranışları alanında gerçekleştirilen araştırmalar incelendiğinde, farkındalığın, özellikle yeni ürünlerin tercih edilme eğilimiyle ilişkili olduğu görülmektedir (Lee ve Shin, 2010: 193; Rezai vd., 2012: 4496). Ayrıca farkındalığın, tüketicilerin mobil uygulamalar aracılı̆̆ıyla konum tabanlı iletişimleri benimsemesini etkilediğini gösteren araştırmalarla da karşılaşılmaktadır (Cottrill, 2015: 132). Shieh ve Hsieh'in (2016: 134) araştırması, müşteriye iletişimler için önce izin almayı ifade eden "opt-in" seçeneği sunulduğunda, diğer yöntemlere göre müşteride daha fazla kullanma eğilimine neden olduğunu göstermiştir. Ayrıca Tsang ve diğerleri ise (2004: 65), özel olarak izin verildiğinde, mobil reklamlara karşı tutumların daha olumlu hale geldiği sonucuna ulaşmıştır. Dolayısıyla konuma dayalı mesajlar alınabileceğine yönelik ve konum tabanlı iletişimler için gereken izin prosedürleriyle ilgili farkındalık düzeyinin, mobil uygulamaların bu özelliklerini kullanma eğilimini etkilemesi mümkündür. Bu kapsamda araştırmanın üçüncü hipotezi aşağıdaki şekilde oluşturulmaktadır.

$\mathrm{H}_{3}$ : Farkındalık, mobil uygulamalar aracılığıyla konum tabanlı iletişimleri benimsemeyi etkilemektedir.

Sosyal psikoloji alanındaki pek çok araştırma, insan davranışlarını öngören davranışsal niyetin, tutumlardan etkilendiğini göstermektedir (Ajzen ve Fishbein, 1977: 888 ; Bagozzi, 1981; 607 Ajzen ve Madden, 1986: 453; Kim ve Hunter, 1993: 331; Vermeir ve Verbeke, 2006: 169 ; Ki ve Hon, 2007: 1; Hartmann ve Apaolaza-Ibáñez 2012: 1254). Ayrıca tutumun, tüketicilerin mobil uygulamaları benimseme eğilimi ile ilişkili olduğunu (Tsang vd., 2004: 65; Muk, 2007: 177; Gao vd., 2010: 574) ve tüketicilerin konum tabanlı mobil mesajları kullanma eğiliminin, tutumlardan etkilendiğini gösteren araştırmalarla da karşılaşılmaktadır (Oh ve Xu, 2003: 679; Richard ve Meuli, 2013: 698). Tezcan ve Yengin'in (2018: 121-122) araştırması ise mesaja (doğru mesaj, kişiye özel, anlamlı mesaj vb.) ve mesaj kaynağına yönelik güvenilirlik değerlendirilmelerinin, konum tabanlı hizmetleri kullanmayı etkilediği sonucuna varmıştır. Dolayısıyla konum tabanlı mobil iletişimleri anlamlı, değerli ve güvenilir bulma gibi olumlu tutumların, bu iletişimleri benimsemeyle ilişkili olması beklenmekte ve araştırmanın dördüncü hipotezi aşağıdaki şekilde oluşturulmaktadır:

$\mathrm{H}_{4}$ : Konum tabanlı mesajlara yönelik tutumlar, mobil uygulamalar aracılığıyla konum tabanlı iletişimleri benimsemeyi etkilemektedir. 


\section{YÖNTEM}

\subsection{Araştırmanın Modeli ve Yöntemi}

Araştırma kapsamında gerçekleştirilen literatür incelemesine göre oluşturulan ve test edilen araştırma modeli Şekil 1.'de görülmektedir.

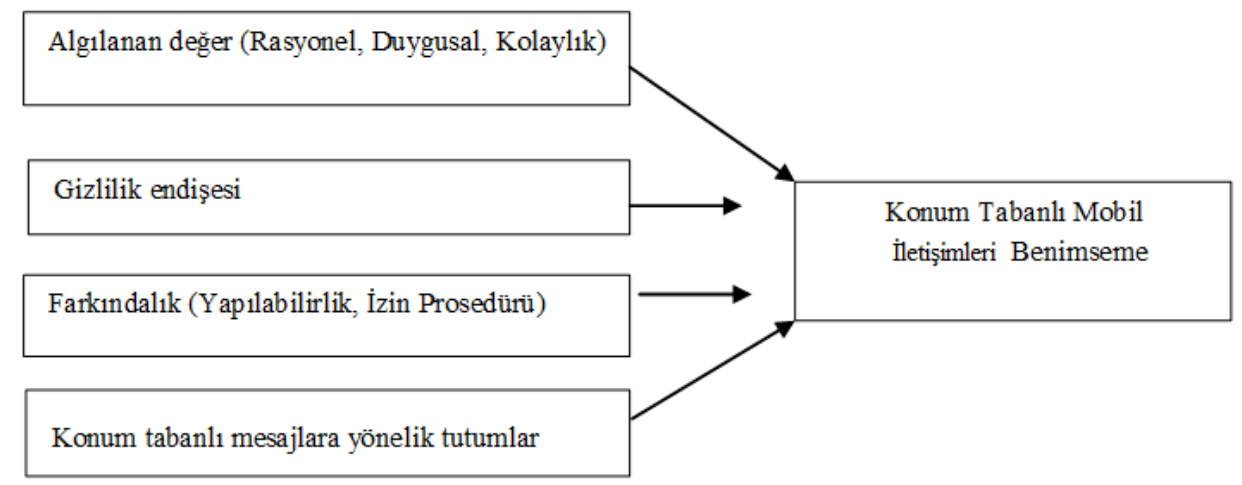

Şekil 1. Araştırma Modeli

Araştırma modelini test etme doğrulusunda, Kırıkkale Üniversitesi İktisadi ve İdari Bilimler Fakültesi öğrencileriyle anket çalışması gerçekleştirilmiştir. Anket formunda öncelikle katılımcılara; konum bilgilerine erişim izni verilen mobil uygulama olup olmadığı, kaç tane mobil uygulamaya konum bilgisine erişim izni verildiği ve izin verilen uygulamalarda konum bilgisine dayalı mesaj alınıp alınmadığı sorulmuştur. Araştırma değişkenlerini belirlemek üzere pazarlama literatüründeki çalışmalardan yararlanılarak oluşturulan ifadeler 5'li Likert (1. Kesinlikle katılmıyorum, 5. Keskinlikle katılıyorum) ölçüm düzeyinde hazırlanmıştır. Ayrıca konum tabanlı iletişimlerden algılanan faydayı ölçmek üzere Hubert vd. (2017) ve Groß'un (2015) araştırmalarından yararlanılmıştır. Algılanan faydanın bir boyutu olarak ifade edilen algılanan kolaylığın ölçülmesi için hazırlanan maddeler için Wu ve Wang vd., (2005) ve Groß’un (2015) araştırmalarından yararlanılmıştır. Tüketicinin gizlilik endişesini belirlemek için ise Zhou (2011) ve Stewart ve Segars'ın (2002) çalışmalarındaki ifadeler araştırmaya uyarlanmıştır. Konum bilgisine dayalı mesajlara yönelik tutumları ölçmek için ise Groß'un (2015) ve Kim vd.'nin (2009) araştırmalarından yararlanılmıştır. Konum tabanlı iletişimleri benimseme değişkenini ölçmek için ise Zhou (2011), Lee (2005), Dabholkar ve Bagozzi, (2002) ve Wu ve Wang'ın (2005) araştırmalarından yararlanılmıştır. Tüm bunların yanında; konum tabanlı iletişimlerin yapılabilirliği ve konum tabanlı iletişimlerde izin prosedürleriyle ilgili farkındalık düzeyini ölçmeye ilişkin maddeler araştırma kapsamında hazırlanmış ve katılımcıların demografik özelliklerine ilişkin sorulara araştırma anketinde yer verilmiştir.

\subsection{Araştırmaya Katılanların Özelliklerinin İncelenmesi}

Araştırmaya katılan 380 lisans öğrencisinin cinsiyete göre dağılımı incelendiğinde \% 59,2'sinin kadın, \% 40,8'inin erkek olduğu tespit edilmiştir. Yaş bakımından ankete katılanların, \%96,6'sının (367 kişi) 18-25 yaş aralığında olduğu tespit edilmiştir. Dolayısıyla katılımcı özelliklerinin birbirine yakın bir yapı sergilediği anlaşılmaktadır.

Araştırmaya katılanların akıllı telefon kullanma süreleri incelendiğinde; \%30,3'ünün (115 kişi) 1-5 yıl arası, \% 48,7'sinin (185 kişi) 6-8 yıl arası ve \%21,1'inin ise (80 kişi) 9 yıl ve üzerinde akıllı telefon kullandıkları tespit edilmiştir. Ankete katılanların \% 83,4'ünün (317 kişi) akılll telefonlarında konum bilgisine erişimine izin verdikleri uygulama/uygulamalar olduğu ve \%54,6'sının (171 kişi) konum bilgisine dayalı olarak işletmelerden ileti aldığ öğrencilerinin çoğu tarafından kullanıldığını göstermektedir. Katılımcıların \%32,2'sinin (98 kişi) 1-2 tane, \%41,1'inin (125 kişi) 3-4 tane ve \%26,6’sının (81 kişi) 5 ve üzerinde uygulamaya konum bilgisine erişim izni verdikleri yapılan anket sonuçlarına göre tespit edilmiştir. Tablo 1.'de akıllı telefon kullanım süreleri ve mobil uygulamaların konum tabanlı özelliklerinin kullanılma durumları özetlenmektedir: 
Tablo 1. Akıllı Telefon Kullanma Süresi ve İzinli Mobil Uygulama Kullanma Durumları

\begin{tabular}{|c|c|c|}
\hline & Q & Geçerli yüzde \\
\hline \multicolumn{3}{|c|}{ Akıllı telefon kullanma süresi } \\
\hline $1-5 y 11$ & 115 & 30,3 \\
\hline $6-8$ yil & 185 & 48,7 \\
\hline 9 yıl ve üstü & 80 & 21,1 \\
\hline Toplam & 380 & 100,0 \\
\hline \multicolumn{3}{|c|}{ Akıllı telefonunuzda konum bilgilerinize erişmesine izin verdiğiniz uygulama var mı? } \\
\hline Evet & 317 & 83,4 \\
\hline Hayır & 63 & 16,6 \\
\hline Toplam & 380 & 100,0 \\
\hline \multicolumn{3}{|c|}{ İzin verdiğiniz uygulamalardan, bulunduğunuz konuma göre işletmelerden ileti aldınız mı? } \\
\hline Evet & 171 & 54,6 \\
\hline Hayır & 142 & 45,4 \\
\hline Toplam & 313 & 100 \\
\hline \multicolumn{3}{|c|}{ Kaç tane mobil uygulamaya konum bilginize erişim izni veriyorsunuz? } \\
\hline $1-2$ & 98 & 32,2 \\
\hline $3-4$ & 125 & 41,1 \\
\hline 5 ve üstü & 81 & 26,6 \\
\hline Toplam & 304 & 100 \\
\hline
\end{tabular}

\subsection{Faktör Analizi}

Araştırma değişkenlerine yönelik hazırlanan maddeler faktör analizine tabi tutulmuştur. Buna göre Kaiser Meyer Olkin katsayısı 0,892 ve Bartlett testi sonuçları anlamlı olarak tespit edilmiştir. Değişkenleri ölçen maddeler, hazırlanış amaçlarına uygun olarak 8 başlık altında toplanmış ve faktörler; "Olumlu Tutum", "Gizlilik Endişesi", "Algılanan Rasyonel Fayda", "Konum Tabanlı Mobil İletişimleri Benimseme”, "Erişim Prosedürü Farkındalığı", "Algılanan Kolaylık", "Algılanan Duygusal Fayda" ve "Konum Tabanlı İletişim Farkındalı̆̆g” olarak adlandırılmıştır. Faktör analizi sonuçları Tablo 2.'de görülmektedir:

Tablo 2. Faktör Analizi

\begin{tabular}{|l|c|}
\hline Maddeler & Faktör Yükleri \\
\hline 1. Faktör: Olumlu Tutum &, 818 \\
\hline Olumludur &, 814 \\
\hline Anlamlıdır &, 797 \\
\hline Değerlidir &, 721 \\
\hline Doğrudur &, 648 \\
\hline Güvenilirdir &, 627 \\
\hline Müşteri çıarlarına uygundur &, 627 \\
\hline Caziptir &, \\
\hline Özdeğer: 11,192, Açıklanan Varyans: 31,978, Toplam Açıklanan Varyans: 31,978, Alfa: 0,928, Ortalama: 3,0650 \\
\hline 2. Faktör: Gizlilik Endişesi &, 867 \\
\hline Çok fazla kişisel bilgimin toplanmasından endişelenirim &, 865 \\
\hline Çok fazla kişiye bilgimi sağlamaktan endişelenirim &, 862 \\
\hline Bilgilerime yetkisiz erişilmesinden endişelenirim &, 860 \\
\hline Konum bilgilerimin onayım dişında başka bir amaç için kullanılmasından endişelenirim &, 827 \\
\hline İzinsiz erişimi engellemek için yeterli önlemin alınmamasından endişelenirim &, 825 \\
\hline Konum bilgilerimin başka kuruluşlara iletilmesinden endişelenirim &, 730 \\
\hline Özdeğer: 5,111, Açıklanan Varyasn: 14,604, Toplam Açklanan Varyans: 46,582, Alfa:0,931 Ortalama: 4,1925 \\
\hline 3. Faktör: Algıllanan Rasyonel Fayda &, 697 \\
\hline İhtiyaçlarıly ilgili/uygun tercihler yapmasını sağlar &, 791 \\
\hline Tasarruf etmesini/uygun fiyatları bulmasını sağlar &, 785 \\
\hline Zaman kazandırır & \\
\hline Daha doğru tercihler yapmasını sağlar & \\
\hline Daha az çaba harcamasını sağlar & \\
\hline
\end{tabular}




\begin{tabular}{|c|c|}
\hline Kişisel beklentileriyle ilgili tercihler yapmasını sağlar & 621 \\
\hline \multicolumn{2}{|l|}{ Özdeğer: 2,410, Açıklanan Varyans: 6,886, Toplam Açıklanan Varyans: 53,468, Alfa: 0,893 Ortalama: 3,4522 } \\
\hline \multicolumn{2}{|l|}{ 4. Faktör: K.T. Mobil İletişimleri Benimseme } \\
\hline İşletmelerin gönderdiği konum bilgime dayalı mesajlardan yararlanmak isterim & 811 \\
\hline Konum bilgimi göz önünde bulunduran kampanya önerilerinden yararlanmak isterim & 791 \\
\hline Konum erişimi isteyen mobil uygulamalara izin vermek niyetindeyim & ,696 \\
\hline Mobil uygulamalarda konum bilgileri hakkında tanıdıklarıma izin vermelerini önereceğim & ,578 \\
\hline \multicolumn{2}{|l|}{ Özdeğer: 1,806, Açıklanan Varyans: 5,160, Toplam Açıklanan Varyans: 58,627, Alfa: 0,895 Ortalama: 3,1132 } \\
\hline \multicolumn{2}{|l|}{ 5. Faktör: Erişim Prosedürü Farkındalı̆̆ı } \\
\hline Konum bilgisine erişimi engellenebilmektedir & 833 \\
\hline Kendiliğinden konum bilgisine erişmemektedir & ,787 \\
\hline İzin/onay almadan konum bilgime erişmemektedir & ,768 \\
\hline Konum bilgisine erişim izni iptal edilebilmektedir & 766 \\
\hline \multicolumn{2}{|l|}{ Özdeğer: 1,453, Açıklanan Varyans: 4,151, Toplam Açıklanan Varyans: 62,778, Alfa: 0,832 Ortalama: 3,7303 } \\
\hline \multicolumn{2}{|l|}{ 6. Faktör: Algılanan Kolaylık } \\
\hline Konum bilgisini sağlaması kolaydır & ,785 \\
\hline Konum bilgisine erişim izni vermesi kolaydır & 751 \\
\hline İşletmeyle etkileşimlerini kolaylaştırır & ,722 \\
\hline İstediği bilgiye ulaşmasını (ürün, mağaza, kampanya, vb.) kolaylaştırır & ,582 \\
\hline \multicolumn{2}{|l|}{ Özdeğer: 1,321, Açıklanan Varyans: 3,774, Toplam Açıklanan Varyans: 66,553, Alfa: 0,817, Ortalama: 3,7343 } \\
\hline \multicolumn{2}{|l|}{ 7. Faktör: Algılanan Duygusal Fayda } \\
\hline Heyecan vericidir & ,841 \\
\hline Eğlencelidir & 825 \\
\hline \multicolumn{2}{|l|}{ Özdeğer: 1,193, Açıklanan Varyans: 3,410, Toplam Açıklanan Varyans: 69, 963, Alfa: 0,897, Ortalama: 2,7039 } \\
\hline \multicolumn{2}{|l|}{ 8. Faktör: K.T. İletişim Farkındalığı } \\
\hline İşletmeler tarafından yapılabilen bir uygulamadır & 846 \\
\hline Mümkündür & ,775 \\
\hline
\end{tabular}

\subsection{Regresyon Analizi ve Hipotezlerin Test Edilmesi}

Araştırma kapsamında oluşturulan hipotezleri test etme doğrultusunda regresyon analizi gerçekleştirilmiştir. Buna göre araştırma modelinde; algılanan fayda ve boyutları, olumlu tutum, gizlilik endişesi, farkındalık ve algılanan kolaylık değişkenlerine modelin bağımsız değişkenler kısmında yer verilmiş ve konum tabanlı mobil iletişimi benimseme değişkeni bağımlı değişken olarak değerlendirilmiştir. Buna göre araştırma modeli anlamlı bulunmuş olup, bağımsız değişkenler, bağımlı değişkenin \% 55'ini açılamaktadır.

Tablo 3. Regresyon Analizi

\begin{tabular}{|l|c|c|c|}
\hline \multicolumn{1}{|c|}{ Bağımsız değişkenler } & Beta & \multicolumn{2}{l|}{ Sig. } \\
\hline Araştırma Modeli/ Bağımlı değişken: Konum Tabanlı İletişimleri Benimseme & 0,101 & 2,191 & 0,029 \\
\hline Kolaylık faydası & 0,015 & 0,348 & 0,728 \\
\hline Duygusal fayda & 0,231 & 4,737 & 0,000 \\
\hline Rasyonel fayda & $-0,175$ & $-4,567$ & 0,000 \\
\hline Gizlilik endişesi & $-0,007$ & $-0,169$ & 0,866 \\
\hline Erişim prosedürü farkındalığ1 & 0,007 & 0,179 & 0,858 \\
\hline Konum tabanlı iletişim farkındalığ1 & 0,487 & 9,648 & 0,000 \\
\hline Olumlu tutum & 62,579 & \multicolumn{3}{|c|}{ Sig. 0,000 } \\
\hline \multicolumn{2}{|c|}{0,742} \\
\hline $\mathrm{R}$ & & 0,551 \\
\hline
\end{tabular}

\section{TARTIŞMA VE SONUÇ}

Neticede, tüketicilerin konuma dayalı aldığı pazarlama mesajlarından (kampanya vb.) yararlanma ve mobil uygulamaların konum tabanlı özelliklerini kullanma eğilimi, işletmelerin bu güncel teknolojik gelişmeden yeterince yararlanması için gereklidir. Zira tüketicilerin benimsemediği bir pazarlama uygulamasının etkili olmasının mümkün olmadığı düşünülmektedir. Dolayısıyla konum tabanlı mobil uygulamaların benimsenmesini artırıcı ve azaltıcı faktörlerin bilinmesi önem arz etmektedir. Kırıkkale Üniversitesinde öğrenim gören öğrenciler ile konum tabanlı mobil pazarlama iletişimleri benimsemesini etkileyen faktörleri 


\section{İ. Bozac1 - R. N. Beğdeş 11/3 (2019) 2084-2093}

belirlemek amacıyla gerçekleştirilen bu çalışma sonuçlarına göre; araştırmaya katılan lisans öğrencilerinin \% 83,4'ünün (317 kişi) akıllı telefonunda konum bilgisine erişme izni verdiği uygulama olduğu ve bu izni verenlerin \% 54,6'inin (171 kişi; toplam katılımcının \% 45'i) konum bilgisine dayalı işletmelerden ileti aldığı görülmüştür. Araştırmada özellikle konuma dayalı daha önce mesaj alanların, konum tabanlı iletişimi benimseme düzeylerinin yüksek olduğu tespit edilmiştir.

Araştırma kapsamında "H1: Algılanan fayda (rasyonel, duygusal, kolaylık), mobil uygulamalar aracılığıyla konum tabanlı mobil iletişimleri benimsemeyi etkilemektedir" şeklinde oluşturulan hipotez kısmi olarak kabul edilmektedir. Çünkü algılanan faydanın alt bileşenleri olan; kolaylık faydası $(\beta=0,101)$ ve rasyonel fayda $(\beta=0,231)$, konum tabanlı iletişimi benimsemeyi etkilerken, duygusal fayda $(\beta=0,015)$ etkilememektedir. Dolayısıyla araştırmaya katılanların konum tabanlı mobil iletişimleri benimsemesinde, bunları eğlenceli veya heyecan verici bulmasının önemli olmadığı, ancak rasyonel faydalar ve kolaylık sağladığına yönelik algılamaların önemli olduğu anlaşılmaktadır. Bu sonuçlar Zhou (2012), Yu vd., (2013), Kang vd., (2015) ve özellikle algılanan faydanın konum tabanlı hizmetlere yönelik davranışsal eğilimi etkilediğini gösteren Pura'nın (2005) çalışmasıyla örtüştüğü görülmektedir. Diğer taraftan Richard ve Meuli (2013) ise üniversite öğrencilerinin konum tabanlı reklamları benimsemede, eğlendiricilik faydasının önemli olduğunu gösteren araştırma sonuçlarından farklılık göstermiştir. Bu durum, konum tabanlı reklamlarda eğlendiricilik faydası önemli bir unsur olmasına karşın, konum tabanlı iletişimler için konum bilgisi sağlamanın müşterilerce kendilerine, bu iletişimleri gerçekleştirmede önemli bir duygusal fayda sağlamadığı şeklinde yorumlanmaktadır.

Araştırmada ikinci olarak "H2: Gizlilik endişesi, mobil uygulamalar aracıllı̆̆ıla konum tabanlı iletişimleri benimsemeyi olumsuz etkilemektedir" hipotezi ise kabul edilmektedir $(\beta=-0,175)$. Bu sonuç, katılımcıların çok fazla kişisel verilerinin toplandığı veya bilgilere yetkisiz erişimlerinden duyduğu kaygının, konum tabanlı mobil iletişimleri benimsemeyi etkileyen bir değişken olduğunu göstermektedir. Bu sonuç Junglas vd. (2008), Basheer ve Ibrahim (2010), Zhou (2011) ve Xu vd.'nin (2011) araştırma sonuçlarıyla örtüşmektedir.

Araştırmanın "H3: Farkındalık, mobil uygulamalar aracılı̆̆ıyla konum tabanlı iletişimleri benimsemeyi etkilemektedir" ş̧eklinde oluşturulan üçüncü hipotezi ise reddedilmektedir. Buna göre erişim prosedürü farkındalığ $1(\beta=-0,007)$ ve konum tabanlı iletişim farkındalığ $(\beta=0,015)$, konum tabanlı mobil iletişimlerin benimsenmesini etkilememektedir. Kısaca araştırmada tasarlandığı şekliyle katılımcıların genel olarak konum tabanlı mobil iletişimleri nasıl kullanacağı ile ilgili farkındalık düzeylerinin, diğer faktörlerle birlikte değerlendirildiğinde önemli olmadığı anlaşılmaktadır. Bu durumun araştırmaya katılan genç tüketicilerin, işletmelerin konuma dayalı mesajlar gönderebildiğinin (katılımcıların \% 4,8'inin verdiği yanıt ortalaması "katılmıyorum" veya "kesinlikle katılmıyorum" düzeyindedir) ve bunun için akıllı telefon ayarlarından mobil uygulamaya konum bilgisine erişim izni verilmesi gerektiğinin (katılımcıların \% 11,9'unun yanıt ortalaması "katılmıyorum" veya "kesinlikle katılmıyorum" düzeyindedir) farkında olmasından kaynaklandığı düşünülmektedir.

Araştırma kapsamında "H4: Konum tabanlı mesajlara yönelik tutumlar, mobil uygulamalar aracıllğıyla konum tabanlı iletişimleri benimseme eğilimini etkilemektedir" şeklinde geliştirilen hipotez kabul edilmektedir $(\beta=0,487)$. Bu sonuç, konum tabanlı mesajlara yönelik tutumların, konum tabanlı mobil iletişimlere yönelik davranış eğilimlerini etkilediğini gösteren Tsang vd. (2004), Muk, (2007) ve Gao vd. (2010), Xu vd. (2009) ve Richard ve Meuli'nin (2013) araştırmalarılla örtüşmektedir. Araştırmada bu değişkenin etkisinin diğer değişkenlerden daha yüksek olduğu tespit edilmiştir.

Araştırmada bağımsız değişkenlerin önem sırasıyla olumlu tutum, algılanan rasyonel fayda, gizlilik endişesi ve algılanan kolaylık faydasının konum tabanlı mobil iletişimleri benimsemede etkili değişkenler olduğu sonucuna varılmaktadır. Bu durum konum tabanlı mesajlara yönelik tüketici tutumlarının olumlu olmasının, bu iletişimleri benimsemede öncelikli bir faktör olduğunu göstermektedir. Dolayısıyla işletmelerin; konuma dayalı mesajların tüketiciler için olumlu, değerli, anlamlı ve müşteri çıkarlarına uygun olduğuna yönelik iletişim çabalarında bulunmasının etkili olması mümkündür. Bunun yanında, tüketicilerin konum tabanlı mesajlar sayesinde daha uygun ürün tercihleri yapmasının mümkün olduğu ve daha az zaman ve çaba harcamasına neden olduğu yönündeki rasyonel fayda algılamalarının artırılmasının da konum tabanlı mobil iletişimleri benimsemeyi artırması mümkündür. Diğer taraftan tüketicilerin kişisel bilgilerine yetkisiz erişim gibi bileşenlerden oluşan gizlilik endişelerinin azaltılmasının konum tabanlı mobil iletişimleri benimsemenin 
önünde giderilmesi gereken bir engel olduğunun işletmelerin farkında olması gerektiği düşünülmektedir. Ayrıca, konum bilgisi sağlamada tüketicilerde kolaylıkla ilgili algılamaların oluşturulması da işletmelerin bu doğrultudaki amaçlarına ulaşmasına katkı sağlayacaktır. Kısaca özellikle genç tüketicilerin konum tabanlı iletişimlerin kullanımını teşvik etmede mobil uygulama geliştiricileri ve işletmelerin; konum tabanlı hizmetlere yönelik olumlu tutum oluşturmak için çaba göstermesi, rasyonel ve kolaylık faydalarını ön plana çıkarması ve gizlilik endişelerini gidermesinin yararlı olacağı düşünülmektedir.

Çalı̧̧ma örnekleminin akıllı telefonu görece yaygın ve sık olarak kullanan lisans öğrencilerinden oluşması, araştırma sonuçlarının genelleştirilmesini engellemektedir. Ancak araştırmadaki model ve bakış açılarından yararlanılarak, konunun yetişkin tüketiciler üzerinde incelenmesi, konuma dayalı mobil iletişimlerde etkili olan faktörlerin genel kullanıcı düzeyinde belirlenmesine katkı sağlayacaktır.

\section{KAYNAKÇA}

Ajzen, I. ve Fishbein, M. (1977). Attitude-behavior relations: A theoretical analysis and review of empirical research. Psychological Bulletin, 84(5): 888-918.

Ajzen, I. ve Madden, T. J. (1986). Prediction of goal-directed behavior: Attitudes, intentions, and perceived behavioral control. Journal of Experimental Social Psychology, 22(5): 453-474.

Ashton, A. S., Scott, N., Solnet, D. ve Breakey, N. (2010). Hotel restaurant dining: The relationship between perceived value and intention to purchase. Tourism and Hospitality Research, 10(3): 206-218.

Bagozzi, R. P. (1981). Attitudes, intentions, and behavior: A test of some key hypotheses. Journal of Personality and Social Psychology, 41(4): 607-627.

Barnes, S.J. (2003). Location-based services. e-Service Journal, 2(3): 59-70.

Basheer, A. A. A. ve Ibrahim, A. A. (2010). Mobile marketing: Examining the impact of trust, privacy concern and consumers' attitudes on intention to purchase. International Journal of Business and Management, 5(3): $28-41$.

Beldona, S., Lin, K. ve Yoo, J. (2012). The roles of personal innovativeness and push vs pull delivery methods in travel oriented location based marketing services. Journal of Hospitality and Tourism Technology, 3 : 86-95.

Bozacı, İ. (2015). Müşterinin Gizlilik Davranışları ile İlişkili Faktörlerin Belirlenmesi. Itobiad: Journal of the Human \& Social Science Researches, 4(3): 612-633.

Cottrill, C. D. (2015). Location privacy preferences: A survey-based analysis of consumer awareness, trade-off and decision-making. Transportation Research Part C: Emerging Technologies, 56: 132-148.

Dabholkar, P. A. ve Bagozzi, R. P. (2002). An attitudinal model of technology-based self-service: Moderating effects of consumer traits and situational factors. Journal of the Academy of Marketing Science, 30: 184201.

Dhar, S. ve Varshney, U. (2011). Challenges and business models for mobile location-based services and advertising. Communications of the ACM, 54(5): 121-128. 124.

Eskiler, E., ve Altunışık, R. (2015). Algılanan değer ve müşteri memnuniyetinin satın alma eğilimleri üzerine etkisi. III. Rekreasyon, 483-493.

Gao, T., Sultan, F. ve Rohm, A. J. (2010). Factors influencing Chinese youth consumers' acceptance of mobile marketing. Journal of Consumer Marketing, 27(7): 574-583.

Groß, M. (2015). Exploring the acceptance of technology for mobile shopping: an empirical investigation among Smartphone users. The International Review of Retail, Distribution and Consumer Research, 25(3): 215-235.

Hartmann, P. ve Apaolaza-Ibáñez, V. (2012). Consumer attitude and purchase intention toward green energy brands: The roles of psychological benefits and environmental concern. Journal of Business Research, 65(9): 1254-1263. 
Hsu, C. L. ve Lin, J. C. C. (2015). What drives purchase intention for paid mobile apps?-An expectation confirmation model with perceived value. Electronic Commerce Research and Applications, 14(1): 46-57.

Hubert, M., Blut, M., Brock, C., Backhaus, C. ve Eberhardt, T. (2017). Acceptance of Smartphone Based Mobile Shopping: Mobile Benefits, Customer Characteristics, Perceived Risks, and the Impact of Application Context. Psychology \& Marketing, 34(2): 175-194.

Junglas, I. A., Johnson, N. A. ve Spitzmüller, C. (2008). Personality traits and concern for privacy: an empirical study in the context of location-based services. European Journal of Information Systems, 17(4): 387-402.

Junglas, I.A. ve Watson, R.T. (2008). Location-based services. Communications of the ACM, 51(3), 65-69.

Kang, J. Y. M., Mun, J. M ve Johnson, K. K. (2015). In-store mobile usage: Downloading and usage intention toward mobile location-based retail apps. Computers in Human Behavior, 46: 210-217.

Ki, E. J. ve Hon, L. C. (2007). Testing the linkages among the organization-public relationship and attitude and behavioral intentions. Journal of Public Relations Research, 19(1): 1-23.

Kim, J., Y. L. Ma, ve J. Park. (2009). Are US Consumers Ready to Adopt Mobile Technology for Fashion Goods?: An Integrated Theoretical Approach. Journal of Fashion Marketing and Management. 13(2): 215-230.

Kim, M. S. ve Hunter, J. E. (1993). Relationships among attitudes, behavioral intentions, and behavior: A metaanalysis of past research, Communication Research, 20(3): 331-364.

Kini, R. B. ve Suomi, R. (2018). Changing Attitudes toward Location-Based Advertising in the USA and Finland. Journal of Computer Information Systems, 58(1): 66-78.

Kuo, Y. F., Wu, C. M. ve Deng, W. J. (2009). The relationships among service quality, perceived value, customer satisfaction, and post-purchase intention in mobile value-added services. Computers in Human Behavior, 25(4): 887-896.

Lee, K. H. ve Shin, D. (2010). Consumers' responses to CSR activities: The linkage between increased awareness and purchase intention. Public Relations Review, 36(2): 193-195.

Lee, T. (2005). The impact of perceptions of interactivity on customer trust and transaction intentions in mobile commerce. Journal of Electronic Commerce Research, 6(3): 165-80.

Liu, C., Marchewka, J. T., Lu, J. ve Yu, C. S. (2004). Beyond concern: a privacy-trust-behavioral intention model of electronic commerce. Information \& Management, 42(1): 127-142.

Muk, A. (2007). Consumers' intentions to opt in to SMS advertising: a cross-national study of young Americans and Koreans. International Journal of Advertising, 26(2): 177-198.

Oh, L. B. ve Xu, H. (2003). Effects of multimedia on mobile consumer behavior: An empirical study of locationaware advertising. 24. Uluslar arası Bilgi Sistemleri Konferansı, ICiS 2003, 679-691.

Ponte, E. B., Carvajal-Trujillo, E. ve Escobar-Rodríguez, T. (2015). Influence of trust and perceived value on the intention to purchase travel online: Integrating the effects of assurance on trust antecedents. Tourism Management, 47: 286-302.

Pura, M. (2005). Linking perceived value and loyalty in location-based mobile services. Managing Service Quality: An International Journal, 15(6): 509-538.

Raza, M. A., Siddiquei, A. N., Awan, H. M. ve Bukhari, K. (2012). Relationship between service quality, perceived value, satisfaction and revisit intention in hotel industry. Interdisciplinary Journal of Contemporary Research in Business, 4(8): 788-805.

Rezai, G., Teng, P. K., Mohamed, Z. ve Shamsudin, M. N. (2012). Consumers awareness and consumption intention towards green foods. African Journal of Business Management, 6(12): 4496-4503.

Richard, J. E. ve Meuli, P. G. (2013). Exploring and modelling digital natives' intention to use permission-based location-aware mobile advertising. Journal of Marketing Management, 29(5-6): 698-719.

Shaharudin, M. R., Pani, J. J., Mansor, S. W. ve Elias, S. J. (2010). Purchase Intention of Organic Food; Perceived Value Overview. Canadian Social Science, 6(1): 70-79. 
Shieh, C. H. ve Hsieh, I. H. (2016). The effects of Location-Based Mobile Marketing between push and on usage intentions. Journal of Advances in Information Technology, 7(2): 134-140.

Stewart, K.A. ve Segars, A.H. (2002). An empirical examination of the concern for information privacy instrument. Information Systems Research, 13: 36-49.

Şahoğlu, C.T. (2018). Kullanımlar ve Doyumlar Yaklaşımı Çerçevesinde Konum Paylaşım Motivasyonları: Foursquare ve Swarm Üzerine Nitel Bir Araştırma. Galatasaray Üniversitesi İletişim Dergisi, 29: 257-278.

Tezcan, E. T. ve Yengin, D. (2018). Halkla İlişkilerin Dijitalleşmesi Bağlamında Konum Tabanlı Pazarlama. İstanbul Aydın Üniversitesi Dergisi, 113-123.

Tsang, M. M., Ho, S. C. ve Liang, T. P. (2004). Consumer attitudes toward mobile advertising: An empirical study. International Journal of Electronic Commerce, 8(3): 65-78.

Vermeir, I. ve Verbeke, W. (2006). Sustainable food consumption: Exploring the consumer attitude-behavioral intention gap. Journal of Agricultural and Environmental Ethics, 19(2): 169-194.

Ververidis, C. ve Polyzos, G. (2002). Mobile marketing using a location based service. First International Conference on Mobile Business, Athens, Greece, 1-12.

Wu, J.H. ve Wang, S.C. (2005). What Drives Mobile Commerce? An Empirical Evaluation of the Revised Technology Acceptance Model. Information\&Management, 42: 719-729.

Wu, L. Y., Chen, K. Y., Chen, P. Y. ve Cheng, S. L. (2014). Perceived value, transaction cost, and repurchaseintention in online shopping: A relational exchange perspective. Journal of Business Research, 67(1): 2768-2776.

Xu H, Oh L, ve Teo H. (2009). Perceived effectiveness of text vs. multimedia location-based advertising messaging. International Journal of Mobile Communication, 7(2):154-177.

Xu, H., Luo, X. R., Carroll, J. M. ve Rosson, M. B. (2011). The personalization privacy paradox: An exploratory study of decision making process for location-aware marketing. Decision Support Systems, 51(1): 42-52.

Yu, J., Zo, H., Kee Choi, M. ve P. Ciganek, A. (2013). User acceptance of location-based social networking services: an extended perspective of perceived value. Online Information Review, 37(5): 711-730.

Zhou, T. (2011). The impact of privacy concern on user adoption of location-based services. Industrial Management \& Data Systems, 111(2): 212-226.

Zhou, T. (2012). Examining location-based services usage from the perspectives of unified theory of acceptance and use of technology and privacy risk. Journal of Electronic Commerce Research, 13(2): 135. 